\title{
IncobotulinumtoxinA and Deep Brain Stimulation
}

\author{
Derrick Soh, Alfonso Fasano
}

\begin{abstract}
Guidelines recommend Botulinum toxin-A (BoNT-A) after deep brain stimulation (DBS), although the effectiveness of their combined use is uncertain. A chart review of Parkinson's disease (17) and dystonia (7) patients undergoing 302 injections with IncobotulinumtoxinA before or after DBS was performed. Patients with cervical dystonia received less IncobotulinumtoxinA after DBS $(290.7 \pm 124.0$ vs. $192.4 \pm 131.4, p=0.005)$ and experienced an increased benefit $(4.0 \pm 3.4$ vs. $8.4 \pm 3.6$ weeks, $p=0.003$ ). No significant differences were found when comparing the treatment outcomes of 14 patients who received both IncobotulinumtoxinA and OnabotulinumtoxinA after DBS. The use of BoNT-A after DBS is a useful strategy although prospective studies are needed.
\end{abstract}

RÉSUMÉ : L'incobotulinumtoxine A et la stimulation cérébrale profonde. Il est des lignes directrices qui recommandent l'incobotulinumtoxine A à la suite de la thérapie de stimulation cérébrale profonde (SCP), et ce, même si l'efficacité de leur utilisation combinée demeure incertaine. Nous avons passé en revue les dossiers de 17 patients atteints de la maladie de Parkinson (MP) et de 7 patients atteints de dystonie ayant reçu 302 injections d'incobotulinumtoxine A avant ou après que des séances de SCP ont été effectuées. Fait à noter, les patients atteints de dystonie cervicale se sont vu injecter moins d'incobotulinumtoxine A après une séance de $\operatorname{SCP}(290,7 \pm 124,0$ contre 192,4 $\pm 131,4 ; \mathrm{p}=0,005)$. Ils ont aussi soutenu avoir ressenti un bien-être accru $(4,0 \pm 3,4$ contre 8,4 $\pm 3,6$ semaines ; $\mathrm{p}=0,003)$. Chez 14 patients ayant bénéficié à la fois d'incobotulinumtoxine A et d'onabotulinumtoxine A, aucune différence notable n'a été observée au moment de comparer l'efficacité de ces deux traitements une fois des séances de SCP complétées. Bref, l'utilisation d'incobotulinumtoxine A après des séances de SCP apparaît comme une stratégie adéquate bien que des études prospectives s'imposent encore.

Keywords: Botox, Botulinum toxin, Deep brain stimulation, IncobotulinumtoxinA, OnabotulinumtoxinA, Xeomin

doi:10.1017/cjn.2019.41

Can J Neurol Sci. 2019; 46: 603-606

Deep brain stimulation (DBS) of the globus pallidus (GPi) or subthalamic nucleus (STN) is an established treatment for dystonia in primary conditions ${ }^{1,2}$ or when it is associated with other neurodegenerative disorders, such as Parkinson's disease (PD). ${ }^{3}$ DBS is particularly indicated when medications or botulinum toxin (BoNT) have failed to provide adequate treatment. Although DBS is highly effective, patients often continue to display dystonic features even after surgery for a series of reasons. In fact, dystonia might not fully respond to DBS in specific body sites or it only resolves with stimulation parameters causing side effects; furthermore, dystonia can be caused by DBS itself. ${ }^{4}$

BoNT serotype A (BoNT-A) has been shown to be beneficial in the treatment of focal and segmental dystonia, with confirmed clinical effectiveness and reasonably safe tolerability profile. ${ }^{5,6}$ Expert opinion-based guidelines recommend the use of BoNT-A in DBS patients in order to treat dystonia in an effective, safe, and focal fashion. ${ }^{5,7}$ To this date, no study has investigated the effectiveness of the combined use of DBS and BoNT.

IncobotulinumtoxinA (Xeomin $®$, Merz Pharma, Frankfurt am Main, Germany) is a BoNT-A complex that differs from other formulations in that it does not have accessory proteins. The significance of this has yet to be fully established although clinical experience confirms its less immunogenicity. ${ }^{6}$ IncobotulinumtoxinA studies of patients with blepharospasm and cervical dystonia have shown it to be non-inferior to
Onabotulinumtoxin A (Botox ${ }^{\circledR}$, Allergan, Irvine, CA, USA) with a $1: 1$ dose ratio. $^{7}$

In this retrospective study, we sought to report the usefulness of IncobotulinumtoxinA in DBS patients. We hypothesized that the combination of DBS and BoNT-A is safe and synergic when used in patients with dystonia. In addition, in patients also receiving OnabotulinumtoxinA, we compared the treatment outcome of the two BoNT-As.

This is a retrospective single-center chart-review of patients seen at the Movement Disorder Centre of the Toronto Western Hospital from 1995 to 2017. Keywords "botulinum toxin," "botox," "xeomin," and "deep brain stimulation" were used in our records search. Inclusion criteria was having undergone DBS and at least one treatment with IncobotulinumtoxinA at any given point in time. The primary outcome was to compare the use, effectiveness, and safety of IncobotulinumtoxinA before and

From the Morton and Gloria Shulman Movement Disorders Centre and the Edmond J. Safra Program in Parkinson's Disease, Toronto Western Hospital, UHN, Toronto, Ontario, Canada (DS, AF); Krembil Brain Institute, Movement Disorders Centre, Toronto, Ontario, Canada (AF)

Received July 19, 2018. Final Revisions Submitted March 25, 2019. Date of AcCePtance March 27, 2019.

Correspondence to: Alfonso Fasano, Professor of Medicine (Neurology) - University of Toronto, Clinician Investigator - Krembil Research Institute, Movement Disorders Centre - Toronto Western Hospital, 399 Bathurst St, 7McL412, Toronto, ON, Canada M5T 2S8. Emails: alfonso.fasano@uhn.ca; alfonso.fasano@gmail.com 
Table 1: Demographics of patients included in the study

\begin{tabular}{l|c|c|c|c|c|c}
\hline $\begin{array}{l}\text { Underlying } \\
\text { Conditions }\end{array}$ & $\boldsymbol{N}$ & DBS target & Mean age (years \pm SD) & Gender (F:M) & $\begin{array}{c}\text { Disease duration } \\
\text { (years } \pm \text { SD) }\end{array}$ & \begin{tabular}{c} 
Severity \\
\hline Parkinsonism
\end{tabular} \\
\hline Cervical dystonia & 17 & STN: 13 GPi: 3 Vim: 1 & $69.1 \pm 6.8$ & $8: 9$ & $22.3 \pm 7.9$ & UPDRS-III: $16.8 \pm 9.2$ \\
\hline Generalized dystonia & 5 & GPi: 5 & $51.25 \pm 11.2$ & $3: 2$ & $\begin{array}{c}\text { BFMMS: } 1.67 \pm 1.2, \\
\text { BFMDS: } 3 \pm 3\end{array}$ \\
\hline MS tremor & 2 & GPi: 2 & $28.5 \pm 4.9$ & $2: 0$ & $28.5 \pm 4.9$ & $\begin{array}{c}\text { BFMMS: } 59.5 \pm 49.4, \\
\text { BFMDS: } 19 \pm 15.6\end{array}$ \\
\hline
\end{tabular}

BFMDS=Burke-Fahn-Marsden Disability Scale; BFMMS=Burke-Fahn-Marsden Movement Scale; GPi=globus pallidus pars interna; MS=multiple sclerosis; STN=subthalamic nucleus; TRS=Fahn Tolosa Marin Tremor Rating Scale; UPDRS=Unified Parkinson Disease Rating Scale; Vim=ventral intermediate thalamic nucleus.

ancluding Parkinson's disease and Lubag disease.

Table 2: Number of sessions, units, sites, duration of effect, and CGI-I and CGI-E according to indication for all patients using IncobotulinumtoxinA after DBS

\begin{tabular}{|c|c|c|c|c|c|c|c|c|}
\hline Indications $(N)$ & Age (years) & No. of sessions & $\begin{array}{c}\text { Mean number of } \\
\text { sessions }\end{array}$ & U/session & Sites/session & $\begin{array}{c}\text { Duration of } \\
\text { effect (weeks) }\end{array}$ & CGI-I & CGI-E \\
\hline $\begin{array}{l}\text { Blepharospasm } \\
\text { (6) }\end{array}$ & $68.2 \pm 4.6$ & 34 & 5.7 & $68.1 \pm 33.7$ & $10.2 \pm 2.5$ & $5.7 \pm 4.2$ & $2.0 \pm 1.0$ & $5.0 \pm 4.4$ \\
\hline Sialorrhea (5) & $65.3 \pm 7.2$ & 29 & 5.8 & $63.1 \pm 23.2$ & $2.2 \pm 0.6$ & $8.0 \pm 4.1$ & $2.0 \pm 0.9$ & $5.1 \pm 3.7$ \\
\hline $\begin{array}{l}\text { Cervical dystonia } \\
\text { (7) }\end{array}$ & $54.6 \pm 12.3$ & 39 & 5.6 & $192.4 \pm 131.4$ & $8.6 \pm 4.2$ & $8.4 \pm 3.6$ & $2.1 \pm 0.9$ & $5.3 \pm 3.5$ \\
\hline $\begin{array}{l}\text { Lower limb } \\
\text { dystonia (6) }\end{array}$ & $65.3 \pm 10.2$ & 23 & 3.8 & $127.0 \pm 73.5$ & $5.6 \pm 3.7$ & $5.1 \pm 4.0$ & $1.9 \pm 0.9$ & $4.7 \pm 3.7$ \\
\hline Total $(24)^{\mathrm{a}}$ & $60.0 \pm 14.0$ & 125 & 5.2 & $118.9 \pm 99.1$ & $6.9 \pm 4.4$ & $7.1 \pm 4.1$ & $2.0 \pm 0.9$ & $5.1 \pm 3.8$ \\
\hline
\end{tabular}

DBS=Deep brain stimulation; CGI-I=Clinical Global Impression Scale - Improvement; CGI-E=Clinical Global Impression Scale - Efficacy.

${ }^{\text {a }}$ Some patients received BoNT-A for more than one indication.

after DBS. Secondary outcome was the comparison between IncobotulinumtoxinA and OnabotulinumtoxinA in patients receiving both.

The following data were retrieved and entered into a standard form: demographic data (age, gender, underlying patient condition, disease duration) and number of treatments. For each treatment, the following data were also recorded: date and number of treatment sessions, type of BoNT-A injected (IncobotulinumtoxinA or OnabotulinumtoxinA), total dose and dilution, and number of sites injected. The severity of dystonia was assessed by dedicated rating scale scores and efficacy of treatment was also expressed by qualitative assessment of duration of effect and Clinical Global Impression (CGI), assessing improvement and efficacy (CGI-I and CGI-E, respectively). ${ }^{8}$ Lastly, any side effects were also documented.

Due to the small sample size, non-parametric Wilcoxon and Mann-Whitney tests were used for paired and unpaired comparison. The test was considered significant when the $p$-value was $<0.05$.

Our search identified 68 patients of which 36 patients met the inclusion criteria. Sufficient clinical information was available for 25 of them (13 females; mean age: $59.4 \pm 14.1$ years). Their underlying conditions include PD ( $n: 17)$, cervical dystonia ( $n: 5)$, generalized dystonia ( $n: 2)$, and multiple sclerosis tremor ( $n: 1)$. The average disease duration and disease rating scales/scores (at the time of undergoing DBS) are shown in Table 1. Indications for BoNT-A treatment were cervical dystonia ( $n$ : 10), blepharospasm ( $n: 7)$, lower limb dystonia $(n: 7)$, sialorrhea ( $n: 5)$, and trunk dystonia ( $n: 2)$.

Five patients underwent a total of 20 sessions of IncobotulinumtoxinA before DBS. Indications were cervical dystonia ( $n: 2)$, generalized dystonia ( $n: 2)$, and foot dystonia ( $n: 1)$. They had all ceased injections at the time of evaluation: two patients ceased injections before surgery due to lack of benefit, whereas three patients continued to have IncobotulinumtoxinA treatment until optimization of DBS settings. The mean number of units used for IncobotulinumtoxinA was $252.5 \pm 120.6$, mean number of sites per session was $9.8 \pm 5.4$, mean duration of effect was $5.1 \pm 2.9$ weeks, mean CGI-I was $2.1 \pm 1.1$, and mean CGI-E was $5.6 \pm 4.3$.

Twenty patients had a total of 282 treatment sessions with BoNT-A after undergoing DBS: 125 sessions using IncobotulinumtoxinA and 157 using OnabotulinumtoxinA. Indications were cervical dystonia ( $n: 7)$, blepharospasm ( $n: 6)$, lower limb dystonia ( $n$ : 6 ), and sialorrhea ( $n: 5)$. The number of sessions, units used, sites per session, duration of effect, and overall effect according to CGI-I and CGI-E for each indication are shown in Table 2. There was an overall moderate effect (CGI-I) of IncobotulinumtoxinA $(2.0 \pm 0.9)$ with minimal side effects (CGI-E: $5.1 \pm 3.8$ ). The average duration effect was $7.1 \pm 4.1$ 
Table 3: Group of patients that have used both IncobotulinumtoxinA and OnabotulinumtoxinA post-DBS

\begin{tabular}{|c|c|c|c|c|c|c|c|c|c|c|c|c|c|}
\hline \multirow[b]{2}{*}{$\begin{array}{l}\text { Indications } \\
(N)\end{array}$} & \multirow[b]{2}{*}{$\begin{array}{c}\text { Age } \\
\text { (years) }\end{array}$} & \multicolumn{6}{|c|}{ IncobotulinumtoxinA Treatment(s) } & \multicolumn{6}{|c|}{ OnabotulinumtoxinA Treatment(s) } \\
\hline & & $\begin{array}{c}\text { No. of } \\
\text { sessions }\end{array}$ & U/session & $\begin{array}{l}\text { Sites/ } \\
\text { session }\end{array}$ & $\begin{array}{c}\text { Duration } \\
\text { of effect }\end{array}$ & CGI-I & CGI-E & $\begin{array}{l}\text { No. of } \\
\text { sessions }\end{array}$ & U/session & $\begin{array}{l}\text { Sites/ } \\
\text { session }\end{array}$ & $\begin{array}{c}\text { Duration } \\
\text { of effect }\end{array}$ & CGI-I & CGI-E \\
\hline $\begin{array}{l}\text { Blepharospasm } \\
\text { (6) }\end{array}$ & $69.0 \pm 4.6$ & 42 & $74.3 \pm 36.5$ & $10.6 \pm 2.5$ & $6.1 \pm 4.4$ & $2.0 \pm 1.1$ & $5.0 \pm 4.7$ & 64 & $55.9 .7 \pm 50.5$ & $9.9 \pm 2.6$ & $5.9 \pm 4.0$ & $2.0 \pm 1.1$ & $5.1 \pm 4.4$ \\
\hline Sialorrhea (2) & $73 \pm 2.8$ & 13 & $73.8 \pm 26.3$ & $2.5 \pm 0.9$ & $8.2 \pm 4.0$ & $1.8 \pm 1.2$ & $4.1 \pm 4.7$ & 19 & $67.2 \pm 16.7$ & $3.1 \pm 1.0$ & $9.3 \pm 4.1$ & $2.2 \pm 0.9$ & $5.8 \pm 3.4$ \\
\hline $\begin{array}{l}\text { Lower limb } \\
\text { dystonia(3) }\end{array}$ & $60.0 \pm 14.1$ & 16 & $110.6 \pm 37.9$ & $4.9 \pm 2.5$ & $3.4 \pm 3.2$ & $2.3 \pm 0.9$ & $6.1 \pm 3.6$ & 8 & $198.1 \pm 114.2$ & $8.1 \pm 3.7$ & $2.0 \pm 4.0$ & $3.0 \pm 1.2$ & $9.0 \pm 4.6$ \\
\hline $\begin{array}{l}\text { Cervical } \\
\text { dystonia (5) }\end{array}$ & $54.0 \pm 14.1$ & 32 & $222.5 \pm 122.2$ & $9.5 \pm 3.8^{*}$ & $8.4 \pm 3.5$ & $2.0 \pm 0.9$ & $5.0 \pm 3.4$ & 62 & $182.7 \pm 128.7$ & $11.5 \pm 3.8 *$ & $9.3 \pm 3.7$ & $1.8 \pm 0.6$ & $4.1 \pm 2.4$ \\
\hline $\begin{array}{l}\text { Truncal } \\
\text { dystonia (1) }\end{array}$ & 50 & & & & & & & 4 & $223.0 \pm 177.3$ & $6.5 \pm 4.1$ & $10.0 \pm 0.0$ & $1.5 \pm 0.7$ & $3.0 \pm 2.8$ \\
\hline Total & $62.5 \pm 11.4$ & 103 & $134.7 \pm 102.5$ & $7.8 \pm 4.2$ & $7.2 \pm 4.1$ & $2.0 \pm 1.0$ & $5.1 \pm 4.1$ & 153 & $126 \pm 117$ & $10.0 \pm 5.0$ & $8.0 \pm 4.0$ & $2.0 \pm 1.0$ & $5.0 \pm 4.0$ \\
\hline
\end{tabular}

DBS=Deep brain stimulation; CGI-I=Clinical Global Impression Scale - Improvement; CGI-E=Clinical Global Impression Scale - Efficacy.

*Significantly different $(p=0.0494)$.

weeks. The blepharospasm group required the most number of injection sites per session $(10.2 \pm 2.5)$ and the lower limb dystonia group required the highest number of total units used per session $(192.4 \pm 131.4)$.

At the time of data collection, eight patients had ongoing treatment and 12 patients had ceased the treatment due to lack of benefit ( $n: 5)$, DBS-related improvement of symptoms ( $n: 2)$, and side effect (headache in one patient). There was no clear documentation for IncobotulinumtoxinA discontinuation in remaining four patients.

There was no significant difference when comparing the use of IncobotulinumtoxinA before and after DBS when looking at the number of sessions, mean number of sites of injection used, average duration of effect, and CGI-I and CGI-E. However, there was a highly significant difference between groups with the number of units used when all conditions were analyzed all together $(252.5 \pm$ 120.6 pre-DBS vs. $118.9 \pm 99.1$ post-DBS, $p<0.001$ ).

With respect to indications, statistical comparison could only be made when IncobotulinumtoxinA was used for cervical dystonia due to small sample size. There was a statistical reduction in the number of units used $(290.7 \pm 124.0$ vs. $192.4 \pm$ $131.4, p=0.005)$ and an increased duration effect (4.0 \pm 3.4 vs. $8.4 \pm 3.6$ weeks, $p=0.003$ )

Fourteen of the 20 patients who received IncobotulinumtoxinA also had OnabotulinumtoxinA treatment. Nine patients were switched to IncobotulinumtoxinA due to no benefit from OnabotulinumtoxinA (7), worsening gait (1), and lack of reimbursement (1). Five patients were switched to OnabotulinumtoxinA due to unknown reasons.

In the eight patients with blepharospasm and in the six patients with cervical dystonia, there was no significant difference in all treatment features except in the number of sites used in cervical dystonia patients $(10.6 \pm 2.5$ with IncobotulinumtoxinA vs. $9.9 \pm 2.6$ with OnabotulinumtoxinA, $p$-value 0.0494) (Table 3).

This retrospective study has shown that the combined use of IncobotulinumtoxinA and DBS is a useful strategy for patients not achieving adequate symptomatic control with DBS alone. Our results show an equivalent efficacy and safety use of IncobotulinumtoxinA before and after surgery with a significant difference in the total number of units used, thus suggesting that there is a synergistic effect of DBS and IncobotulinumtoxinA. Findings also show that IncobotulinumtoxinA has effect and safety similar to other studies: a latency of 1-2 weeks and a peak effect at 8 weeks and moderate improvement in GCI scale.,

There is very little evidence of the combined safety and efficacy of DBS and BoNT-A and no evidence currently comparing the effectiveness of BoNT-A before and after DBS. A short report in a group of six patients with foot dystonia post-DBS has shown that there was an improvement with OnabotulinumtoxinA, with a duration effect of approximately 5 months, ${ }^{10}$ a figure substantially longer than in our cohort, the longest being 8.4 weeks. Increasing dose of BoNT-A may have resulted in longer duration of effect.

Previous studies have shown that there is no difference of efficacy in IncobotulinumtoxinA and OnabotulinumtoxinA in the treatment of blepharospasm, cervical dystonia, and leg dystonia. ${ }^{7}$ This was also seen in our results.

There are several limitations to this study, such as the small sample size (before and after DBS) and the non-blinded and retrospective analysis. In addition, patients receiving BoNT-A before and after DBS were not the same, further challenging our hypothesis that these two treatments are synergic. Furthermore, the lack of dedicated rating scales before and after treatment and a formal quantitative assessment of duration effect after each treatment represent other limitations. Lastly, results with OnabotulinumtoxinA have to be interpreted with caution as it was not the main focus of the study and we collected incomplete data for patients using OnabotulinumtoxinA.

In conclusion, in spite of the limits of our retrospective study, we suggest that IncobotulinumtoxinA is useful to use in conjunction with DBS and the availability of BoNT-A as treatment after DBS should not be forgotten. There exists a possibility that DBS may have an additive effect on patients needing BoNT-A and may be useful in patients that were previously resistant to BoNT-A. A prospective double-blind study is certainly needed for patients who have undergone DBS, a population excluded from BoNT-A trials thus far.

\section{DisClosures}

The study was funded by a grant from Merz. DS has nothing to disclose. AF reports grants, personal fees, and non-financial support from Abbvie; grants, personal fees, and non-financial support from Boston Scientific; grants, personal 
fees, and non-financial support from Medtronic; personal fees from Chiesi; personal fees and non-financial support from Ipsen; personal fees from UCB; and grants and personal fees from Sunovion, outside the submitted work.

\section{Statement of Authorship}

DS: execution and writing of the first draft. AF: conceptualization of the study, revising the manuscript, and final approval of the version to be published.

\section{REFERENCES}

1. Vidailhet M, Vercueil L, Houeto JL, et al. Bilateral deep-brain stimulation of the globus pallidus in primary generalized dystonia. N Engl J Med. 2005;352(5):459-67.

2. Volkmann J, Wolters A, Kupsch A, et al. Pallidal deep brain stimulation in patients with primary generalised or segmental dystonia: 5-year follow-up of a randomised trial. Lancet Neurol. 2012;11(12):1029-38

3. Gurevich T, Peretz C, Moore O, et al. The effect of injecting botulinum toxin type A into the calf muscles on freezing of gait in Parkinson's disease: a double blind placebo-controlled pilot study. Mov Disord. 2007;22:880-3.
4. Baizabal-Carvallo JF, Jankovic J. Movement disorders induced by deep brain stimulation Parkinsonism Relat Disord. 2016; 25:1-9. doi: 10.1016/j.parkreldis.2016.01.014

5. Albanese A, Barnes MP, Bhatia KP, et al. A systematic review on the diagnosis and treatment of primary (idiopathic) dystonia and dystonia plus syndromes: report of an EFNS/MDS-ES Task Force. Eur J Neurol. 2006;13:433-444.

6. Ricciardi L, Bove F, Fasano A. Xeomin(®) use in patients with systemic immune reactions to other botulinum toxins type A. Eur J Neurol. 2013;20(3):e45-6. doi: 10.1111/ ene. 12076

7. Hallett M, Albanese A, Dressler D, et al. Evidence-based review and assessment of botulinum neurotoxin for the treatment of movement disorders. Toxicon. 2013;67:94-114. doi: 10.1016/ j.toxicon.2012.12.004

8. Busner J, Targum SD. The Clinical Global Impressions Scale. applying a research tool in clinical practice. Psychiatry (Edgmont). 2007;4(7):28-37.

9. Rieu I, Degos B, Castelnovo G, et al. Incobotulinum toxin A in Parkinson's disease with foot dystonia: a double blind randomized trial. Parkinsonism Relat Disord. 2018;46:9-15. doi: 10.1016/ j.parkreldis.2017.10.009.

10. Gupta AD, Visvanathan R. Botulinum toxin for foot dystonia in patients with Parkinson's disease having deep brain stimulation: a case series and a pilot study. J Rehabil Med. 2016; 48(6):559-62. doi: 10.2340/16501977-2094 